\title{
NOXIOUSNESS OF THE AFRICAN WHITE STEM BORER, MALIARPHA SEPARATELLA RAG (PYRALIDAE: PHYCITINAE) IN IRRIGATED PADDY FIELDS AT LAKE ALAOTRA (MADAGASCAR)
}

\author{
G. BIANCHI ${ }^{1}$, B. RASOLOARISON ${ }^{2}$ and M. GENINI ${ }^{3}$ \\ ${ }^{1}$ Institute of Plant Sciences, Swiss Federal Institute of Technology, \\ Clausiusstr. 21/CLS, 8092 Zurich, Switzerland; \\ ${ }^{2}$ Subdivision Régionale de la Protection des Végétaux (S.R.P.V.), \\ Station Alaotra 503, Madagascar; \\ ${ }^{3}$ Project "Protection intégrée en riziculture au Lac Alaotra" \\ (PLI), B.P. 30, Station Alaotra 503, Madagascar
}

(Received 13 May 1992; accepted 19 November 1993)

\begin{abstract}
A study of the noxiousness of the African white rice stem borer, Maliarpha separatella Rag carried out under controlled field conditions has revealed that the impact of this pest on the yield and its components is assessable. For mean infestation rates up to $68 \%$ during the period of highest sensitivity of a paddy rice culture (second half of tillering to panicle initiation), no significant decrease could be observed in the number of panicles, nor any significant increase in the number of white heads and the number of empty grains per hill. However, with increasing infestation rates, the number of immature panicles increased and the number and weight of filled grains per hill decreased. An explorative analysis of the infestation rate-yield loss relationship, showed that a sigmoid model describes this interdependence appropriately. The proposed economic injury level (EIL), is here considered more the result of an approach, which had as its goal the re-definition of the status of the pest than as an instrument of a chemical control programme with treatments based on an action threshold.
\end{abstract}

KeyWords: Madagascar, rice stem borers, Maliarpha separatella, Phycitinae, yield loss, economic injury level, integrated pest management

Résumé-Zne étude de la nuisibilité du borer blane africain du riz, Maliarpha separatella Rag. conduite en plein champ et en conditions contrôlées, montre que l'impact de ce phytophage sur le rendement et ses composantes est mesurable. Des infestations moyennes allant jusqu'à $68 \%$ des tiges infestées au moment de plus grande sensibilité de la culture (deuxième moitié du tallage jusqu'à l'initiation paniculaire) n'ont aucun effet sur le nombre total de panicules, sur le nombre de têtes blanches et sur le nombre de grains stériles par touffe. On observe par contre une augmentation du nombre de panicules immatures et une diminution du nombre et du poids des grains fertiles. Une analyse explorative de la relation taux d'infestation-perte de rendement montre qu'un modèle de type sigmoïde décrit cette interdépendance de façon convenable. Le seuil d'intervention proposé dans la deuxième partie de ce travail n'est pas consideré comme l'outil d'une stratégie de traitment au seuil mais comme le résultat d'une approche qui avait comme but la redéfinition du statut de ce phytophage.

Mots Clés: Madagascar, foreurs du riz, Maliarpha separatella, Phycitinae, pertes de rendement, seuil de tolérance, protection intégrée 


\section{INTRODUCTION}

Among rice stem borers, the African white rice stem borer, M. separatella, is considered the most common species on the African continent (Pollet, 1981; Njoka et al., 1982; Akinsola, 1984; Akinsola and AgyenSampong, 1984; Ho, 1986).M. separatella has almost exclusively been reported on cultivated rice (Oryza sativa $\mathrm{L}$. and $O$. glaberrima Steud.), but it has also been found on $O$. longistaminata Chev. and Roehr and on $O$. punctata Kotschy ex Steud (Brenière et al.,1962; Akinsola and Agyen-Sampong, 1984). The occurrence of this species on plants other than the genus Oryza, has been reported only on Andropogon tectorum in West Africa (Anonymous, 1977) and on Echinochloa holubii in Swaziland (PANS, 1970). Outside the African continent it has never been reported as a rice stem borer. $\mathrm{Li}(1985)$ mentioned it as an important pest of sugar-cane in Papua New Guinea and Sandhu and Chander (1975) as a phytophage of sorghum in the Punjab. The description given by these two authors and their use of the common name "green-striped borer", however, indicate that this species is not the same as the one known from Africa. In our opinion, $M$. separatella is probably a monophagous species and its distribution may be restricted to the sub-Saharan region of Africa.

The impact of $M$. separatella on rice yield is difficult to assess as the damage caused to the rice plant is not visible at first sight. On the common rice varieties cultivated at Lake Alaotra, even heavy infestations do not lead (or almost not) to the appearance of white heads or dead hearts.

In South East Asia and on the African continent, white heads or dead hearts are usually associated with the attacks of other stem borers such as Chilo suppressalis Walker,Scirpophaga incertulas Walker (PANS, 1970; FAO, 1971), Diopsisthoracica Westw. and D. apicalis Dalm. (Akinsola and AgyenSampong, 1984; Ho, 1986). The appearance of white heads or dead hearts can be used for the quantification of yield losses on the basis of their incidence during a growing period of the rice plant. On the other hand, in Madagascan rice fields these symptoms are mainly associated with sporadic infestations of Sesamia calamistis Hamps. and Hydrellia sp.

Almost all the authors who deal with African and Madagascan rice entomology agree that there is an absence of a clear interdependence between the attacks of $M$. separatella and the appearance of white heads and dead hearts, both for irrigated and rainfed rice varieties. This fact can be explained by the behaviour of the caterpillars. They generally complete their life cycle isolated in the lower internodes of the rice plant and they only feed on the central stem-parenchyma without destroying the conducting vessels (Pollet, 1981).
The study of the noxiousness of the African white rice stem borer has been one of the main tasks of the research project PLI ("Protection intégrée en riziculture au Lac Alaotra, Madagascar"). This project, supported by the Swiss Development Cooperation, was started in 1983 with the objective of developing an integrated pest management programme in rice. The results of intensive experiments carried out during the rice growing seasons 1985 to 1989 (PLI 19851989) show that the yield loss due to $M$. separatella is very difficult to quantify outside controlled field conditions. The high dispersion capacity of the newly hatched larvae, which show a clear preference for well developed tillers, does not allow the quantification of the loss on the basis of natural infestations.

\section{MATERIALS AND METHODS}

\section{Influence of the attack on the yield and its components}

During the rice growing season 1986, in the first week of January, 30 nylon-organza net cages of 3.24 $\mathrm{m}^{2}$ each (64 rice hills, $20 \times 20 \mathrm{~cm}$ spacing) were installed in a rice field, where the local variety Makalioka 34 (MK 34) had been transplanted on 15 December 1985. The plants in the cages were artificially infested at 58 days after transplanting (DT), at the end of maximum tillering, which represents the most sensitive crop growth stage. This period lasts about 4 weeks from the second half of tillering until panicle initiation. First-instar larvae (L1) hatched from egg masses collected in rice fields and kept individually in the laboratory, were used for the artificial infestation under the cages. Three infestation levels with six repetitions each were considered: 55,110 and $220 \mathrm{~L} 1$ per 100 tillers. The experiment included 12 further cages: 6 non-infested (control) cages and 6 exposed to natural infestations of $M$. separatella after $58 \mathrm{DT}$. The experiment was conducted within a randomized block design. The total number of hills considered was 1080 ( 36 centre hills of each cage $x$ six cages per infestation level $x$ four infestation levels, plus the hills of six control cages). To observe the age structure of the infesting stem borer cohorts, other hills infested under cages at the same period were dissected weekly. Cages were removed one month later at the end of the development of the infesting generation so as to permit the undisturbed development of the crop. The formerly encaged fields were then chemically protected with Decis ${ }^{\circledR}$ (deltamethrin) until harvest to prevent infestation through successive stem borer generations. This allows the precise estimation of the infestation level due to the attacks of $M$. separatella during the sensitive period of the crop. The 36 centre hills of each cage were harvested separately. The following 
parameters were registered for each hill: $\%$ of infested tillers, number of tillers, fertile panicles, white heads, immature panicles, the number and weight of fertile and empty grains. The influence of the attacks on the yield and its components was analysed regressively.

\section{Infestation rate-yield loss model}

The relationship between the relative paddy yield per hill and cage $(Y)$ with the mean tiller infestation per cent per cage (INF) was first analysed by the application of a simple linear regression model (eqn. 1).

$$
Y=a \cdot I N F+b
$$

eqn. 1

In order to take into account the great variability observed within hills of the same cage, we proceeded to a further analysis by considering only 16 centre hills of each cage as independent observations. That means we were obliged to test by an analysis of the variance the absence of significant differences between the blocks in terms of the reaction of the hills to the attacks. As a criterion for the homogeneity of the crop, we chose the ratio between the percentage infestation per hill (after transformation into arcsin $[\sqrt{ }$ inf $/ 100])$ and the average yield per panicle. The 480 hills ( 30 cages with 16 hills per cage) was submitted to a further regression analysis, without distinction of the infestation levels. The statistical procedure used, LOWESS (Locally weighted regression and smoothing scatterplot) (Cleveland, 1979), is based on the minimum least square method and is particularly useful for the explorative analysis of large amount of observations.

\section{Economic injury level (EIL)}

The economic injury level model used in this paper is defined as the lowest population density of a pest which causes an economic loss (Stern et al., 1959). From this very simple, but historically important concept, the following equation (eqn. 2) is derived.

$$
C=E \cdot V \cdot R \cdot P
$$

with

$C=$ Management cost (Madagascan Francs (FMG) per ha).

$E=$ Efficiency of the chemical treatment (= reduction rate of the pest population).

$V=$ Expected crop value (FMG per kg paddy).

$R=$ Expected yield in the absence of the pest $(\mathrm{kg}$ paddy per ha).

$P=$ Expected yield loss ratio as a function of the pest infestation level.
The monetary value of the expected yield loss caused by the pest should be at least the same as the cost of the chemical protection $(C)$. Here this value $(C)$ is obtained through the multiplication of the yield loss ratio caused by $M$. separatella $(P)$ with the expected yield in the absence of the pest $(R)$ and with the crop value $(V)$. The use of the constant $E$, which defines the efficiency of the chemical control, becomes necessary when the reduction rate of the pest population is less then $100 \%(E=1.0)$. If we substitute $P$ (eqn. 2) with 1 - $Y$, i.e.- $a . I N F$ (eqn. 1), which stands for the yield loss ratio as a function of the pest infestation level, and then rearrange the equation for $I N F$, we obtain the per cent infestation at harvest which would have justified the crop protection (eqn. 3 ).

$$
I N F=\frac{C}{E \cdot V \cdot R \cdot-a}
$$$$
\text { eqn. } 3
$$

The crop protection against $M$. separatella must obviously be realized during the sensitive period of the rice culture. The EIL (eqn. 4) will therefore be expressed best in numbers of fresh egg masses per 100 tillers cumulated during the sensitive period of the rice culture to the attacks.

$$
E I L=\frac{100}{T S . O E} \cdot \frac{C}{E . V . R .-a} \quad \text { eqn. } 4
$$

In this experiment, the percentage infestation (INF) observed at harvest corresponded only to the attacks of $M$. separatella during the sensitive period of the crop. This permits us to express $I N F$ simply in numbers of fresh egg masses considering an appropriate estimation of the pre-imaginal survival per cent $(T S)$ and the fertility of the infesting generation $(O E)$.

\section{RESULTS AND DISCUSSION}

\section{Influence of the attack on the yield and its components}

During the period of highest sensitivity of the rice crop, mean tiller infestation rates per infestation level up to $68.2 \%$ did not have any influence on the number of panicles $(P=0.93)$ and on the number of empty grains per hill $(P=0.86)$. The influence of the attacks on the number of white heads is little $(P=0.14)$. On the contrary, we observed an increasing number of immature panicles $(P=0.02)$, a decreasing number of fertile grains per hill $)(P=0.009)$ and a diminution of the weight of 1000 grains $(P=0.06)$ (Table 1$)$.

If we compute a simple regression analysis between the relative paddy yield per hill and per cage 
Table 1. Impact of Maliarpha separatella on the rice yield and its components. All the data refers to the hill and all the weights are in grams. The standard deviations of the means for $n=6$ cages per infestation level are in italic

\begin{tabular}{lrrrrrrr}
\hline INF & \multicolumn{1}{c}{ PA } & WH & GP & \multicolumn{1}{c}{ WE } & \multicolumn{1}{c}{ FG } & \multicolumn{1}{c}{ EG } & \multicolumn{1}{c}{ WT } \\
\hline 5.6 & 10.324 & 0.014 & 0.046 & 28.502 & 1100.384 & 129.028 & 25.907 \\
& 0.561 & 0.015 & 0.045 & 0.908 & 42.063 & 12.507 & 0.226 \\
24.3 & 10.343 & 0.042 & 0.046 & 25.483 & 958.523 & 107.620 & 26.594 \\
& 0.602 & 0.049 & 0.055 & 3.633 & 139.012 & 29.106 & 0.153 \\
54.7 & 10.176 & 0.070 & 0.247 & 22.575 & 902.836 & 126.075 & 25.006 \\
& 0.867 & 0.038 & 0.123 & 1.550 & 62.874 & 18.100 & 0.189 \\
60.8 & 10.702 & 0.107 & 0.181 & 21.527 & 865.040 & 116.273 & 24.898 \\
& 1.295 & 0.048 & 0.067 & 1.154 & 54.295 & 15.560 & 0.303 \\
68.2 & 10.190 & 0.051 & 0.269 & 20.868 & 855.454 & 120.009 & 24.405 \\
& 0.767 & 0.032 & 0.129 & 1.685 & 73.922 & 25.603 & 0.327 \\
\hline
\end{tabular}

INF: tiller infestation per cent at harvest.

PA: number of panicles.

WH: number of white heads.

GP: number of green immature panicles.

WE: net paddy yield.

FG: number of filled grains.

EG: number of empty grains.

WT: weight of 1000 grains.

( $Y$ in $\mathrm{g}$ ) and the mean tiller infestation per cent per cage $(I N F)$, we obtain a linear significant decrease of the yield (Fig. 1):

$Y=-0.00385 . I N F+1.0000\left(R^{2}=0.63, n=30, P<\right.$ 0.001 )

The analysis of variance confirmed the absence of significant differences between the blocks in the

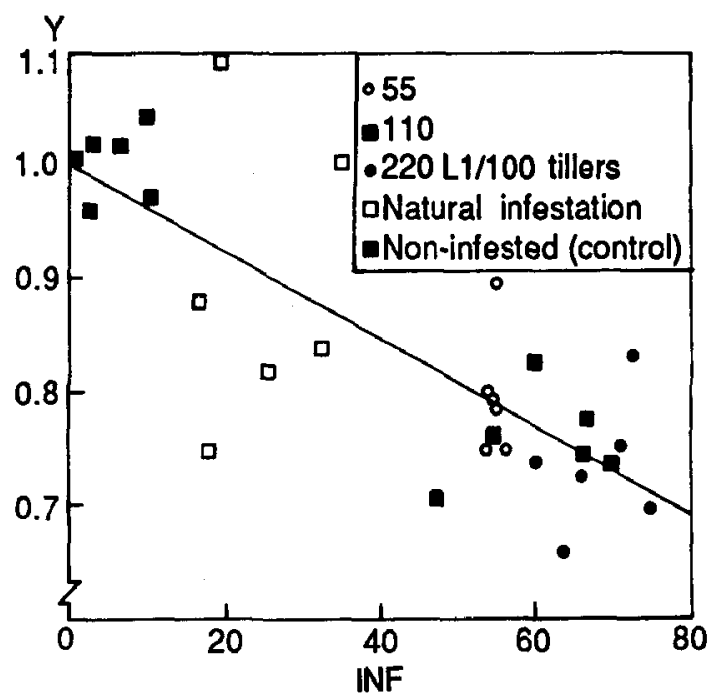

Fig. 1. Relationship between the relative paddy yield per hill and cage ( $Y$ in $g$ ) with the mean tiller infestation per cage at harvest (INF in \%). The artificial infestation under the cages took place at the end of the tillering period of the rice culture, during the period of highest sensitivity of the crop. The different symbols correspond to the different initial infestation levels. reaction of the hills to the attacks [Fcal (blocks) $=$ $0.457, \mathrm{Df}=449, P=0.81]$. This permitted us to regroup all the hills of the experiment and to use them as independent observations. If we then explore with the statistical procedure LOWESS the relationship between infestation rate and yield at the hill level, we realize that a non linear model could describe better this interdependence(Fig. 2). The observed variability is important, but it is also characteristic for this type

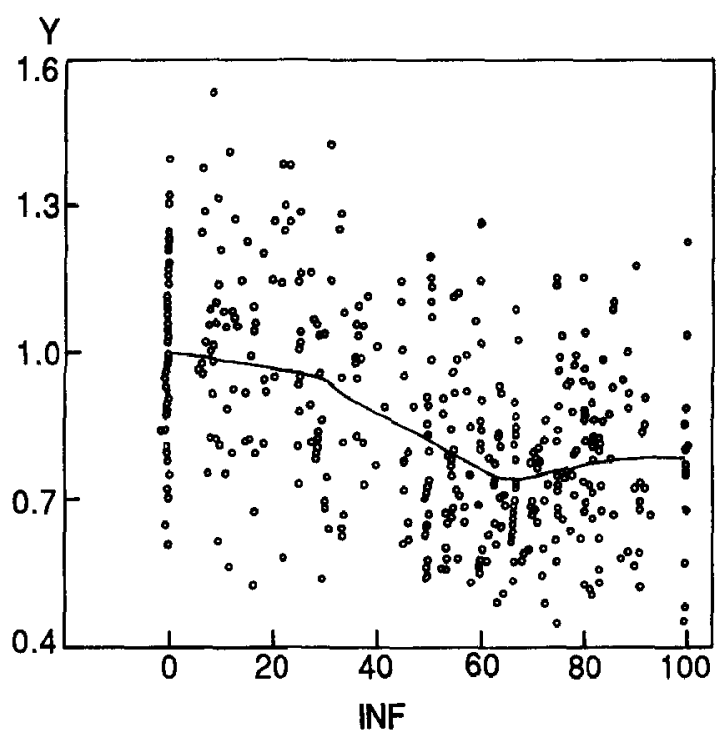

Fig. 2. Relationship between the relative paddy yield per hill ( $Y$ in $g$ ) with the mean tiller infestation per cent per hill (INF). The whole data set $(n=478$ hills $)$ has been submitted to a smoothing procedure (Cleveland, 1979). 
of experimentation. The sigmoid shape of this curve looks the same for several agricultural pests in different cultivated ecosystems. This shape refers to a known biological reality and it emphasizes three distinct portions: (1) no loss or compensation phase (about 0 to $30 \%$ infestation), (2) phase in which the loss is linear proportional to the intensity of the infestation (about 30 to $60 \%$ infestation) and (3) phase of maximum loss (about 60 to $100 \%$ infestation). Looking at other insect pests, this phase of maximum loss is usually attained at very high population densities because of the intraspecific competition for food (Hodkinson and Hughes, 1982). For $M$. separatella, 60 to $100 \%$ infestation corresponds to a mean density of only 1.0 to 1.6 caterpillars per tiller. The high dispersion capacity of the $\mathrm{Ll}$ and the mortality due to competition during its installation inside the internodes of the rice plant do not allow higher population densities even at high infestations. Because of this and the fact that the feeding behaviour of the caterpillars, which complete their cycle inside the lower internodes without destroying the conducting vessels, there appears to be no spectacular damage.

\section{Economic injury level (EIL)}

The parameters used for the estimation of the EIL (eqn. 4) are as follows:

\begin{tabular}{|c|c|}
\hline Number of eggs per egg mass ${ }^{1}$ & $O E=42.0$ \\
\hline $\begin{array}{l}\text { Survival per cent of the infesting } \\
\text { generation }{ }^{1}\end{array}$ & $T S=17.0$ \\
\hline $\begin{array}{l}\text { Efficiency of the chemical } \\
\text { treatment }{ }^{1}\end{array}$ & \\
\hline Expected crop value ${ }^{2}$ & $50 \mathrm{FMG}$ \\
\hline Yield loss ratio & .00385 \\
\hline
\end{tabular}

'PLI, 1986, 1987

${ }^{2}$ Crop value at the end of the rice season $1990(1000$ $\mathrm{FMG}=1.3$ US $\$$ )

The EIL is expressed in cumulated egg masses per 100 tillers. According to an enumerative sampling plan, at least 40 quadrats with $0.25 \mathrm{~m}^{2}$ each, should be taken per field every week to correctly estimate the egg batch density over the sensitive period of the crop (Bianchi et al., 1989). The EIL shown at Fig. 3 is calculated for three different cost levels of the chemical control measures $(20,000,40,000$ and 60,000 FMG per ha, for treatments which ensure protection with $70 \%$ efficiency during the sensitive phase of the crop, i.e. 4 weeks) and as a function of expected yields ranging from 1500 to $4500 \mathrm{~kg}$ paddy per ha.

This EIL model was implemented during the past six rice growing seasons in the whole region of Lake

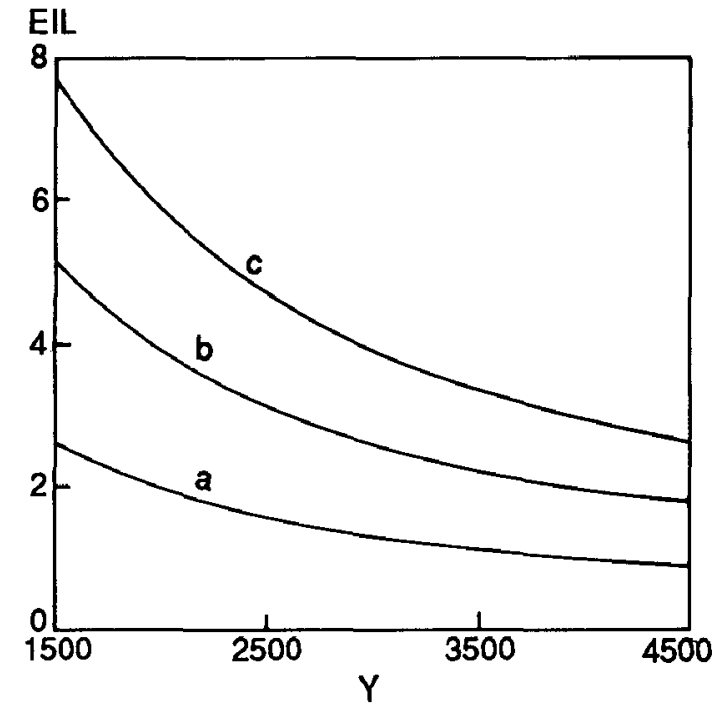

Fig. 3. Estimation of an economic injury level (EIL, eqn. 4) for Maliarpha separatella. The EIL is expressed in number of fresh egg masses per 100 tillers cumulated during the sensitive period of the rice culture to the attacks. It is calculated for three different cost levels of chemical control measures (a: 20,000; b: 40,000 ; $60,000 \mathrm{FMG}$ per ha, for treatments which ensure protection during the sensitive period of the crop, i.e. 4 weeks), and as a function of expected yields ranging from 1500 to $4500 \mathrm{~kg}$ paddy per ha. The crop value is $250 \mathrm{FMG}$ per $\mathrm{kg}$ [1000 FMG = US\$1.3 (1990)].

Alaotra (about 70,000 ha of mostly irrigated paddy rice). The data concerning the infestation levels of the rice fields was collected by scouting teams of the local Plant Protection Section. The existence and support of an efficient warning system within a good organized extension service is of fundamental importance for the success of the proposed IPM programme. The experience gained in the implementation of this EIL model reveals that the following points should be carefully considered:

(1) There are two important data which influence a decision in favour of a chemical treatment: the estimation of the egg mass density of $M$. separatella during the sensitive phase of the crop, and the estimation of the expected yield loss. The infestation rate-yield loss relationship (Fig. 2) is a component of the EIL model which is al ways associated with an important variability which should be taken into account.

(2) The economic and technical components of this model, as the real (non subsidized) costs of the chemical applications $(C)$, the effective control ratio of the pest achieved through ground applications by the farmers $(E)$, the commercialized proportion of the yield $(R)$ and the expected marked value $(V)$, are quite difficult to estimate correctly and they are often treated 
subjectively. A detailed discussion of these components is nearly impossible because of their complexity and their interaction with secondary variables such as weather, soil factors, biotic factors and the human social environment (Pedigo et al., 1986).

(3) The EIL model considers the interaction between the population densities of $M$. separatella and the phenology of the rice culture, but not the influence of the chemical applications on the age structure and on the population dynamics of this (and of other) pests. From a strictly economic point of view, the model is appropriate in the case of single applications but it does not necessarily represent the best strategy in the case of multiple applications (Mumford and Norton, 1984). For multiple applications (as in the case of M. separatella), it would be preferable to use a dynamic type of action threshold that optimizes the application numbers and timing, on the basis of a population model (Shoemaker, 1984). The computation of an EIL derived from this type of approach presupposes however, that the farmers aim to maximize their profit.

(4) There is little knowledge about the influence of pesticides on the rice entomofauna. The appearance of negative secondary effects is nevertheless almost inevitable (FAO, 1988). Investigations on the flora and fauna associated with the rice culture, Lake Alaotra have shown that irrigated rice fields have a very high biodiversity. Only among the arthropods, over 800 species have been captured, some of them, as for example some leafhoppers, are important secondary pests in tropical Asia. Because of the underestimation of the long term ecological costs, a crop protection based on an action threshold should therefore be considered from the beginning, as only a short term control measure.

\section{CONCLUSIONS}

The influence of the attacks of the African white stem borer, $M$. separatella on yield and its components is assessable. The impact of $M$. separatella on the yield has already been the object of several investigations, but remains economically neglected in most of the African rice ecosystems (Pollet, 1981; Ho et al., 1983; Akinsola, 1984; PLI, 1985-1989; $\mathrm{Ho}, 1986$ ). The rice culture in the Madagascan region of Lake Alaotra is not an exception in this matter. In the actual production system, marked by considerable intensification difficulties (Blanc-Pamard, 1986), $M$. separatella represents for the local Plant Protection

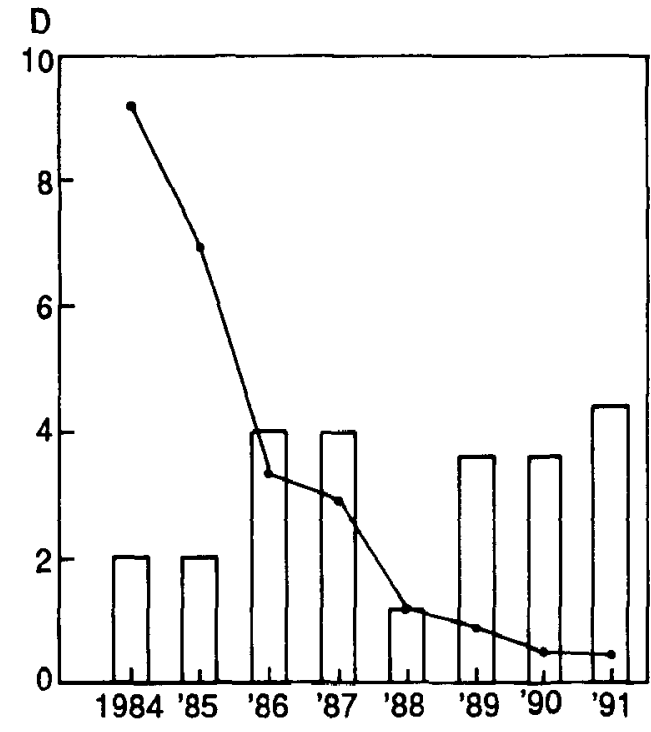

Fig. 4. Evolution of the mean infestation level of Maliarpha separatella at the end of the sensitive period of the crop (line) and of the EIL which has been applied by the local Plant Protection Section (columns) in the southern part of Lake Alaotra since 1984. The reasons for the decreasing infestations are not yet clear. Since 1985 the expanding cultivation of rice varieties with shorter growth periods lead to a deterioration of the temporal coincidence between pest and rice culture. This is the most common explanation for the observed decrease of the infestation. (D: number of fresh egg masses per 100 tillers, cumulated during the sensitive period of the crop).

Section, what we would call a "borderline case".

The proposed EIL model is calculated following a very simple concept of a more entomological than economical character (Stern et al., 1959; Mumford and Norton, 1984). It is rather considered as the result of an approach, which had as its goal the redefinition of the status of a pest considered a key pest of the Madagascan rice culture (Brenière et al., 1962; MPARA, 1984), than as an instrument for a chemical control programme with treatments based on an action threshold (Fig. 4).

An IPM programme based exclusively on an EIL approach postpones the pest problem, because it does not look at its causes. The actual research occurring in Madagascar within the IPM project of the Swiss Cooperation, evaluates three different biological control measures: the augmentative release of the indigenous oophagous parasitoid Telenomus applanatus Bin and Johnson (Hym. Scelionidae), the introduction of exotic parasitoids from the African continent, and the use of entomopathogens. A more global approach to the rice ecosystem (PLI, 19851989; Baumgärtner et al., 1989; Bianchi et al., 1990) 
could lead to the application of biological control measures which would allow the EIL concept to be abandoned.

\section{REFERENCES}

Akinsola E. A. and Agyen-Sampong M. (1984) The ecology, bionomics and control of rice stemborers in West Africa. Insect Sci. Applic. 5, 6977.

Akinsola E. A. (1984) Effects of rice stem-borer infestation on grain yield and yield components. Insect Sci. Applic. 5, 91-94.

Anonymous (1977) Special Research Project, Annual Report of the West African Rice Development Association(WARDA), No. 3, Monrovia, Liberia.

Baumgärtner J., Regev U., Rahalivavololona N., Graf B., Zahner P. and Delucchi V. (1989) Rice production in Madagascar, regression analysis with particular reference to pest control. Agric. Ecosystems Environ. 30, 37-47.

Bianchi G., Baumgärtner J., Delucchi V., Rahalivavololona N., Skillman S. and Zahner P. (1989) Sampling egg batches of Maliarpha separatella Rag. (Lep.,Pyralidae) in Madagascan rice fields. Trop. Pest Manage. 35, 420-424.

Bianchi G., Baumgärtner J., Delucchi V. and Rahalivavololona N. (1990) Modèle de population pour la dynamique de Maliarpha separatella Ragonot (Pyralidae, Phycitinae) dans les rizières malgaches du Lac Alaotra. J. Appl.Entomol. 110, 384-397.

Blanc-Pamard C. (1986) Autour du riz, le difficile face-à-face des paysans et de la SOMALAC dans la cuvette du Lac Alaotra (Hautes Terres centrales de Madagascar), Collection Documents Systèmes Agraires, Département Systèmes Agraires du CIRAD, Montpellier, No. 6, 461-479.

Brenière J., Rodriguez H. and Ranaivosoa H. (1962) Un ennemi du riz a Madagascar, Maliarpha separatella Rag. ou borer blanc. L'Agron. Trop. 17, 223-301.

Cleveland W. S. (1979) Robust locally weighted regression and smoothing scatter plots. J. Am. Stat. Assoc. 74, 829-836.

FAO (1971) Crop loss assessment methods. FAO Manual on the Evaluation and Prevention of Losses by Pests, Disease and Weeds. FAO by the Commonwealth Agricultural Bureaux, Alden Press, Oxford.

FAO (1988) Integrated Pest Management in Rice in Indonesia. Status after three crop seasons, perspectives for farmers training in Jakarta, May 1988.

Ho D. T. (1986) Damage and yield loss caused by stem borers in irrigated rice in Kenya. Trop. Agric. 63, 201-204.

Hodkinson M. K. and Hughes I. D. (1982) Insect Herbivory. Chapman and Hall, London.

Li C. S. (1985) Sugar cane insect pests with special reference to the moth borers in the Markham Valley, Papua New Guinea. MUSHI 50, 13-18.

MPARA (Ministère de la Production Agricole et de la Réforme Agraire de la République Démocratique de Madagascar) (1984) TaonaZina II, Rapport d' exécution pour la campagne 1984.

Mumford J. D. and Norton G. A. (1984) Economics of decision making in pest management. Annu. Rev. Entomol. 29, 157-174.

Njokah J., Kibuka G. and Raina A. K. (1982) Some aspects of population dynamics of Maliarpha separatella (Rag.) on rice in the Lake Basin areas of Kenya. Insect Sci. Applic. 3, 271-273.

PANS (1970) Pest control in rice. PANS Manuals (Pest Articles and News Summaries), No. 3, Publ. in Britain by the Ministry of Overseas Development.

Pedigo L. P., Hutchins S. H. and Higley L. G. (1986) Economic injury levels in theory and practice Annu. Rev. Entomol. 31, 41-68.

PLI (1985-1989) Protection intégrée en riziculture au Lac Alaotra (Madagascar), République Démocratique de Madagascar et Confédération Suisse (DDA). Institut de Phytiatrie, EPF, Zürich. Rapports d'Activité Nos. 1 (1985), 2 (1986), 3 (1987), 4 (1988), 5 (1989).

Pollet A. (1981) Maliarpha separatella Ragonot (Pyralidae, Phycitinae) sur riz irrigué en Côte d'lvoire Centrale, Travaux et documents de I'ORSTOM No. 140, Paris.

Sandhu G. S. and Ramesh Chander(1975) Occurrence of green striped borer, Maliarpha separatella Ragonot on sorghum in Punjab. J. Bombay Nat. Hist. Soc. 72, 3, 872-873.

Shoemaker C. A. (1984) The optimal timing of multiple applications of residual pesticides: deterministic and stochastic analyses. In Pest and Pathogen Control: Strategic, Tactical, and Policy Models (Edited by Conway G. R.). International Series on Applied Systems Analysis, John Wiley and Sons, London.

Stern V. M., Smith R. F., Van den Bosh R. and Hagen K. S. (1959) The integrated control concept. Hilgardia 29, 81-101. 